\title{
O Memorial Padre Carlos: formas e maneiras de escrever a história da escola
}

Jardel Costa Pereira

Jussara Gallindo Mariano de Carvalho

Universidade do Estado de Minas Gerais

(UEMG)
Priest Carlos Memorial: ways and means to write the history of a school

\section{Resumo}

Esse artigo tem como objetivo analisar a importância de um memorial escolar na preservação de documentos e objetos escolares, fundamentais para a escrita e o entendimento da história da escola e do pensamento educacional brasileiro. O Memorial Padre Carlos, da Escola Profissional Dom Bosco, de Poços de Caldas (MC), após uma parceria com o Centro de Memória - Unicamp, passou a ser um exemplo de organização de várias materialidades, escolares ou não, que possuem uma história a ser escrita e interpretada.

Palavras chave: Memorial; História; Escola.

\section{Abstract}

This paper aims to analyze the importance of school memorials to preserve objects and documents that are fundamental for writing and understanding the history of the Brazilian educational thinking and school system. Priest Carlos Memorial, located at Dom Bosco Professional School, in Poços de Caldas, Minas Cerais state, aftera partnership with Centro de Memória - Unicamp became an example of organization of several school and non-school materialities, which have a history to be written and interpreted.

Keywords: Memorial; History; School. 


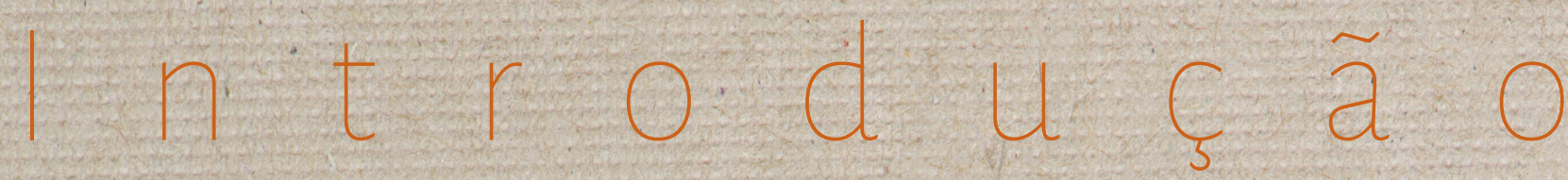

á várias for-
mas de se
escrever a história de uma escola, o que implica diretamente na escrita da história da Pedagogia.

A maneira escolhida e apresentada nesse artigo é a da história escrita a partir de um memorial escolar, que pode ser um importante local, em que se encontram documentos que relam como era a escola no passado, identificando, assim, sua importância e seu sentido histórico. O manejo de fontes documentais e de arquivo, assim como a consolidação de um centro de memória educativa e pedagógica, apresentam-se como possibilidades de preservação da materialidade histórica, através da consolidação de um espaço de aprendizado/treinamento para futuros pesquisadores. Este lá vârias formas de se escrever a história de uma escola, o que implica diretamente na escrita dahistória da Pedagogia

A maneira escolhida $\mathrm{e}$ apresentada nesse artigo é a da história escrita a partir de um memorial escolar, que pode ser um importante local, em que se encontram documentos que relam como era a escola no passado, identificando, assim, stla importância e seu sentido histórico. tipo de organização possibilita, junto ao aporte teórico, atrair jovens estudantes da área da História, Pedagogia, licenciaturas e de outras áreas, para estudos e pesquisas. Outro aspecto relevante sobre a organização da memória do espaço escolar é o de perceber como um sujeito social constrói os seus objetos de estudo e a sua intelectualidade, e como esses podem ser utilizados como objeto de análise pela História e por diversas áreas do conhecimento.

Santos (2015, p. 43) destaca a importância do memorial para a escrita da história da escola, sendo que, ao citar Furtado (2009), certifica que as instituições escolares apresentam-se; na atualidade, como um dos espaços de maior relevân- 
cia para as pesquisas em história da educação.

No parecer de Mogarro (2006), os arquivos escolares devem salvaguardar e preservar diversos tipos de fontes, que se constituirão em importantes instrumentos para a história da educação na construção de uma memória educativa:

A sua importância tem vindo a ser reconhecida, conduzindo a uma reflexão sobre a sua preservação, as condições de instalação, a organização correcta dos documentos e o acesso às informações que nele estão contidas. Os arquivos escolares constituem o repositório das fontes de informação diretamente relacionadas com o funcionamento das instituições educativas, o que lhes confere uma importância acrescida nos novos caminhos da investigação em educação, que colocam estas instituições numa posição de grande centralidade para a compreensão dos fenômenos educativos e dos processos de socialização das gerações mais jovens (MOCARRO, 2006, p. 71)

O Memorial Pe. Carlos é um dos poucos museus de escolas que constam no mapa cultural do estado de Minas Cerais, mas já se destaca por sua organização e sua importância como referência para outras instituições que se aliem a esta perspectiva de preserva- ção da história da educação no Brasil. Investigar a importância de seu acervo e a sua contribuição para o contexto, social, cultural e educacional da cidade de Poços de Caldas e da região sul de Minas Gerais se torna relevante para fomentar as pesquisas e a produção do conhecimento, bem como para elucidar aspectos relevantes da influência desta instituição para a comunidade em que está inserida, estabelecendo-se como um desafio para os historiadores da educação:

Os historiadores da educação só recentemente se têm vindo a ocupar da arqueologia material da escola, dando atenção aos silêncios da história do ensino e superando o esquecimento da intrahistória da escola e da especificidade própria das instituições educativas (MOGARRO, 2006, p. 79).

São poucas as escolas no Brasil e até mesmo em vários países que contam com um local específico para guardar e preservar a sua arqueologia escolar, o que não é o caso da Escola Profissional Dom Bosco (EPDB), pois além de possuir um memorial, este encontra-se muito bem organizado, possuindo um vasto acervo documental. Todavia, outro desafio que se apresenta é lidar e interpretar esse presente tão real em 
que caem por terra as especulações, as interpretações e as deduções, ficando somente o que realmente é, nos seus propósitos e intenções.

Nessa conjuntura, encontra-se tambémo pensamento deMogarro (2006), que ao escrever sobre a realidade dos arquivos escolares de Portugal, acena para um campo geral da história da educação que vem se renovando, seja por meio de novas abordagens, novos locais, novos métodos de pesquisa e claro, velhos e novos desafios:

Situamo-nos numa zona de fronteira, de cruzamento, das novas perspectivas da história da educação, da história cultural, da história social e também das ciências da educação. Assiste-se a uma renovação das problemáticas teóricas e de uma reinvenção dos terrenos de pesquisa, das fontes de informação, das práticas de investigação e do apetrechamento metodológico, em que a perspectiva historiográfica se afirma face às antigas abordagens de matriz essencialmente sociológica. A afirmação de uma história que se reclama de um pensamento cultural crítico estabelece uma agenda de diálogo entre as preocupações do presente e as realidades do passado, num esforço de compreensão em que se interrogam estas últimas para alcançar a inteligibilidade dos tempos presentes (MOCARRO, 2006, p. 79).
Entender um arquivo escolar, a lógica de sua construção e organização, da exposição de sua materialidade, da concentração em alguns atores sociais ou até mesmo da negligência de outros, das suas intenções explícitas ou implícitas, é poder, no aqui e agora, dar sentido real e não ilusório, ao que vem sendo feito e realizado na preservação da história da escola, valorizando a memória viva, atual e presente, por meio de depoimentos orais, pois muito se tem perdido de nossa história por causa da dependência de documentos escritos, esquecendo-se de que, quando o documento não existe, os relatos podem preencher essas lacunas.

Para que se construa um processo de pesquisa sobre história da Educação no Brasil, é necessário que a preservação e organização da materialidade deste processo se estabeleça nas instituições educativas do país:

O que é recente no campo da história da educação e, especificamente, da história das instituições educativas como âmbito de estudo na história da educação é uma tentativa de escrever a história das instituições escolares rompendo com a perspectiva descritiva e com os registros oficiais da escola (NORONHA, 2007, p. 165).

Este rico campo a ser explorado, de 
acordo com Carvalho (2008, p. 6), apresenta a possibilidade de ir além da mera descrição para a pesquisa histórica "tanto como uma 'unidade em ação', como um 'sistema de práticas', criando, desta forma, um rico campo para ser explorado com vistas à compreensão dos sistemas sociais e da sociedade em geral".

Assim, será necessário, na análise das instituições, correlacioná-las com as condições sociais nas quais emergiam segundo contextos histórico-geográficos determinados. [...] trata-se de se formular a questão: a quem se destina a instituição que estou me propondo a reconstruir e que resultados ela pretende atingir com a ação empreendida? (SAVIANI, 2007, p. 25)

Saviani (1994) mostra a importância de compreender a história da educação prioritariamente a partir da escola, e a escola no contexto do capitalismo. Sanfelice (2007, p. 77) apresenta outra dimensão sobre as instituições escolares, entendendo-as como "a síntese de múltiplas determinações, de variadíssimas instâncias (política, econômica, cultural, religiosa, da educação geral, moral, ideológica etc.) que agem e interagem entre si, 'acomodando-se' dialeticamente", e construindo, a partir desta dinâmica, um processo de identidade.
Castanho (2007, p. 41) fundamenta-se nos escritos do historiador Justino Magalhães (2005), demonstrando que, em uma perspectiva que aborde as várias dimensões e acepções na busca pelos mais diversos tipos de fontes, se construirão também as suas várias dimensões, abrangendo desde a micro até a macro história, distanciando-se da mera descrição de práticas internas, e articulando todas as dimensões ao contexto e as especificidadés que o campo sustenta.

De acordo com Sanfelice (2005b), nesta perspectiva a história das instituições escolares estará intimamente ligada ao processo político, legislativo e ao sistema de ensino e nível educacional aos quais a instituição estará atrelada, demarcando, desta forma, suas especificidades, e indicando um processo de construção de seu histórico, que trará diferença tanto para a materialidade de suas fontes históricas quanto para os sujeitos envolvidos neste processo:

Cada instituição pode ter origem relevante para um estudo histórico, muitas vezes, ligado aos movimentos sociais, à população à qual atende e suas lutas e conflitos de classe, podendo trazer im- 
portantes contribuições para se compreender como uma determinada comunidade se desenvolveu e, também, como as políticas educacionais influenciaram a trajetória dessa instituição, bem como de uma determinada comunidade (CARVALHO, 2008, p. 8).

Nesse contexto, se faz importante observar as relações do processo histórico das instituições, na busca das mais diversas fontes, em suas relações com o contexto social. Considerando que "a historiografia das instituições escolares ainda não possui método formalizado, estruturado sobre uma base canônica" (NORONHA, 2007, p. 79), o caminho para a construção da identidade deve contemplar suas múltiplas determinações:

É, pois, como dimensão da totalidade histórica que a historiografia das instituições escolares precisa ser escrita para superar as lacunas e as ausências de respostas que foram deixadas pela chamada, história tradicional, porque estas ausências de respostas têm origem na ausência de perguntas, porque a realidade não responde nada espontaneamente. É preciso ter indagações e clareza teórica e metodológica do lugar teórico de onde se está falanido (do seu alcance e limites) para que seja possível fazer avançar a compreensão do objeto e dos modos de se tratar o objeto nas, relações que se estabelecem entre sujeito objeto no proćesso de construção do conhecimento histórico (NORONHA, 2007, p. 83, grifo do autor)

Assim, a dimensão da totalidade po-1 derá possibilitar o olhar mais amplo, dando o necessário fôlego para a transformação de meros materiais guardados nas instituições em verdadeiras fontes para os acervos históricos das instituições, fomentando a busca por mais espaços que possibilitem estudos históricos como o memorial apresentado neste artigo.

O contato com o acervo escolar fará total diferença para o pesquisador, pois este trará a dimensão do potencial de seu trabalho, que é a busca por respostas aos questionamentos de sua investigação; as relações estabelecidas no desenvolvimento poderão não só modificar as hipóteses primordiais de uma pesquisa como suscitar novas questões. Alguns estudos já indicam que, na legislação brasileira, há um suporte para que os acervos escolares sejam devidamente preservados e organizados, favorecendo assim a pesquisa científica (CARVALHO, 2008).

Sobre o caráter jurídico destes acervos, Medeiros (2004) ressalta que o arquivo escolar mostra-se também a 
partir da figura do pesquisador como facilitador para a pesquisa científica e que é um direito da comunidade possuir arquivos organizados:

Conjunto de documentos produzidos ou recebidos por órgãos públicos, instituições de caráter público e entidades privadas, em decorrência do exercício de atividades específicas, bem como, pessoa física, qualquer que seja o suporte da informação ou a natureza dos documentos. [...] o arquivo escolar será o conjunto de documentos produzidos ou recebidos por escolas públicas ou privadas, em decorrência do exercício de suas atividades específicas, qualquer que seja o suporte da informação ou a natureza dos documentos (MEDEIROS, 2004, p. 1).

Por conseguinte, o autor indica que estes acervos são patrimônio de interesse público e devem ser protegidos por lei: "as escolas particulares exercitama liberdade de ensino, mas exercem múnus público, pois para isso são autorizadas ou reconhecidas" (MEDEIROS, 2004, p. 1).

Apesar da obrigatoriedade da preservação da documentação da escola pela legislação, observa-se ainda um descaso com vários aspectos envolvidos, o que torna necessário um olhar mais detido para essas fontes escola- res e uma gestão apropriada para a sua preservação:

Para a democratização da pesquisa e do conhecimento, para a produção de saberes, os pesquisadores da História da Educação precisam elaborar propostas, exigir o cumprimento do princípio de franqueamento de documentos à consulta, que só poderá ser otimizado com acervos bem organizados. [...] Não existir arquivos organizados com lugar para a pesquisa é descumprir o princípio legal (MEDEIROS, 2004, p. 9).

Miguel (2007) e Vidal (2007) mostram alguns pontos que demarcam as dificuldades para a efetivação da pesquisa em arquivos escolares, como a falta de interesse por parte do poder político e a falta de uma organização técnica de tais acervos. Para Migual (2007, p. 32), "O questionamento da educação escolar, quer pelo áspecto das políticas educacionais, quer pela cultura escolar, leva o pesquisador à escola, por ser esse um espaço concreto de realização de todo um sistema de transmissão de transmissão e de construção de saber" (MIGUEL, 2007, P. 32).

Questões como técnicas de arquivamento, de conservação e manuseio do material dos acervos são enfatizadas por Vidal (2007), mostrando que este 
aprendizado poderá trazer um maior envolvimento do alunado da instituição e da comunidade, além da ampliação da noção de documento escolar:

Durante este processo aprendiam a respeitar o patrimônio cultural e arquivístico e compreendiam o significado da educação para a cidadania. [..] O acompanhamento do desenrolar do projeto deixava evidente os ganhos que a atividade trazia para a formação de alunos e professores. O envolvimento que demonstravam tanto nas tarefas mais manuais do arquivamento quanto nas mais intelectuais da análise documental da documentação atestava a proficuidade da iniciativa. No entanto, os ganhos não se circunscreveram à sensibilidade destes sujeitos. Ao ser organizado pelo corpo docente e discente, o arquivo suscitou o interesse de toda a comunidade escolar que passou a doar documentos para o acervo compondo o Centro de Memória (VIDAL, 2007 p. 63).

\section{A Escola Dom Bosco e o Memorial Padre Carlos}

A partir de uma pesquisa bibliográfica, analisam-se por meio desse artigo alguns trabalhos que tanto estudaram como utilizaram o acervo do Memorial Padre Carlos, fundamentando assim a importância que esses acervos têm tanto para um historiador como também para profissionais de outras áre-, as, que poderão, a partir de múltiplas materialidades, escrever em várias perspectivas a respeito da história de um determinado centro educacional.

A dissertação de mestrado de Carvalho (2008), que trata da educação profissional, teve como suporte para a pesquisa o Memorial Pe. Carlos, que se localiza dentro da Escola Profissional Dom Bosco, na cidade de Poços de Caldas, no estado de Minas Cerais. A escola foi fundada pelo Padre Carlos Henrique Neto ${ }^{1}$, importante liderançá religiosa da cidade, responsável por uma atuação precursora, ao criar, no ano de 1946, o Clube Recreativo dos Anjos de Cara Suja (CRACS), um clube de futebol para reunir meninos em situação de rua:

\footnotetext{
1 Nascido em 1914, Carlos logo demonstrou um profundo interesse pelo sacerdócio, ordenando-se padre bem jovem. Como padre secular, iniciou suas atividades sacerdotais na cidade de Divisa Nova (MG). Foi transferido para a sua cidade natal, Poços de Caldas, na década de 1940. Nessa época, o religioso protagonizou, em conjunto com a Profa. Maria Aparecida Figueiredo, a fundação da Escola Profissional Dom Bosco, que até os dias de hoje é escola referência na cidade e região: "Essa instituição escolar foị e ainda é responsável pela formação de grande parcela dos trabalhadores da cidade de Poços de Caldas, por sua proposta de profissionalização dos alunos" (ALVISI, 2008, p. 1).
} 
A Escola Profissional Dom Bosco teve seu início provocado pela inquietação de um padre secular frente à situação dessas crianças. Capelão do Hospital Santa Casa da Misericórdia e do Asilo São Vicente de Paula, Padre Carlos Henrique Neto, em 1946, ao repreender um menino negro durante a celebração de uma missa, pensou que, em vez de punir, não seria possível auxiliar algumas crianças pobres da cidade. Sempre envolvido com o ensino de crianças pertencentes às classes populares, ao perceber o tálento de um menino para as atividades de desenho, conseguiu uma sala para que Maria Figueiredo - professora que conhecia desde os tempos da meninice - começasse um trabalho nesse sentido. Portanto, Padre Carlos e Maria Figueiredo, juntos, passaram a ser os responsáveis pela organização e estruturação da escola. Logo, vários meninos os procuraram, sendo necessário providenciar outras alternativas para ensiná-los (ALVISI, 2008, p. 91)

As práticas esportivas foram a semente da Escola Profissional Dom Bosco (2007), exercendo um papel importante do ponto de vista da investigação, pois, no que diz respeito a projetos educacionais direcionados à crianças e jovens pertencentes às classes populares de Poços de Caldas, possibilitou uma educação profissionalizante gratuita, até o final de 1982, para aqueles que buscavam, nas ruas, recursos para sobrevivência.
O memorial da Escola Profissional Dom Bosco tem uma gestão que privilegia a preservação de seu acervo, cuja organização conta com o envolvimento da comunidade, de ex-alunos, de ex-professores e até de voluntários sem qualquer vínculo anterior com a escola. Ao mesmo tempo em quezela e preserva um acervo com a história do passado, também realiza, dia após dia, o registro e arquivamento dos fatos e acontecimentos do presente. A sua consolidação também contou com a participação efetiva da professora e pesquisadora Lilian de Cássia Alvisi, que a partir da elaboração de sua dissertação de mestrado (ALVISI, 2001) passou a se envolver com a escola e, consequentemente, com os anseios da comunidade escolar em criar um memorial. A historiadora, em sua tese de doutorado, relembrou quais foram as estratégias iniciais para a organização do Memorial Pe. Carlos:

Inicialmente, houve a convocação de uma reunião emergencial, com o objetivo de discutirmos estratégias de resistência que possibilitassem um movimento de recuperação e preservação da história da Escola Profissional Dom Bosco. Como pesquisadora da Faculdade de Educação da Unicamp e pertencente à comunidade de Poços de Caldas, coordenei, a pedido 
da direção da escola, o processo de mobilização de um grupo significativo de pessoas que manifestasse interesse em apoiar essa proposta. Dos segmentos da comunidade elegemos: pais, professores, coordenadores, diretores, funcionários, tanto atuais como aqueles que mantinham vínculo com a escola, devido à sua importância passada na construção da história da instituição. Membros da sociedade civil foram também convocados, levando em conta suas relações, tanto com a história da Escola Profissional Dom Bosco, como com instituições relacionadas à educação e à memória de Poços de Caldas: representantes da Secretaria de Educação; Divisão de Cultura; Direção do Museu Histórico e Ceográfico; membros do Conselho de $\mathrm{Pa}$ trimônio Histórico, profissionais da área de engenharia e arquitetura vinculados aos projetos de recuperação da história da cidade; professores das Universidades Pontifícia Católica de Minas Gerais e Estadual de Minas Cerais; e representantes de empresas que em momentos distintos atuaram e apoiaram a implantação e o funcionamento dos cursos profissionalizantes (ALVISI, 2008, p. 5)

A partir desse movimento inicial, várias foram as reuniões que culminaram na efetivação de sua criação, sendo que a preocupação final norteou-se em encontrar uma instituição que orientasse e fornecesse treinamentos de como organizar todo o acervo da escola:
Uma vez organizada a equipe representada pela comunidade em seus múltiplos aspectos e traduzindo um desejo coletivo de preservação das memórias da Escola Profissional Dom Bosco, uma outra preocupação tornou-se pertinente: a procura por uma instituição que tivesse competência teórica e conhecimentos técnicos específicos na recuperação e preservação da memória. Como na cidade não havia tal tipo de instituição, procuramos o Centro de Memória- Unicamp; em setembro de 2002 (ALVISI, 2008, p. 8)

Passados mais de dez anos de sua existência, o memorial continua mantendo a missão que fundamentoú sua criação: preservara memória da Escola Profissionalizante Dom Bosco, como também oferecer aos pesquisadores uma estrutura organizacional que facilite a busca por fontes com assuntos específicos, presentes em suas diversificadas materialidades. A maneira como se consolidaram as estratégias de gestão do memorial e também a visão futurista de sua constituição em preservar a memória do tempo presente, produziu um espàço que pode ser tomado como exemplo constitutivo para outros memoriais:

As reuniões promovidas pela Comissão de Implantação do Memorial aconteceram periodicamente para discussões que envolveram a necessidade da obtenção de apoiadores e patrocinadores, a forma- 
ção da equipe que representaria diferentes segmentos da comunidade, planos:e projetos para a realização de exposições permanentes e itinerantes, adoção de critérios para a seleção dos documentos a serem arquivados, elaboração dos projetos e dos relatórios a serem apresentados pela Lei de Incentivo Municipal e Estadual, organização dos encontros com os especialistas do CMU, redação de artigos para a publicação nos jornais internos e locais. Enfim, os problemas, conquistas e desafios foram compartilhados com a equipe que tomava decisões, coletivamente (ALVISI, 2008, p. 244)

A fotografia a seguir (Imagem 1) apresenta a capa de um exemplar de um

Imagem 1 - Capa do livro atualmente exposto no Memorial Pe. Carlos.

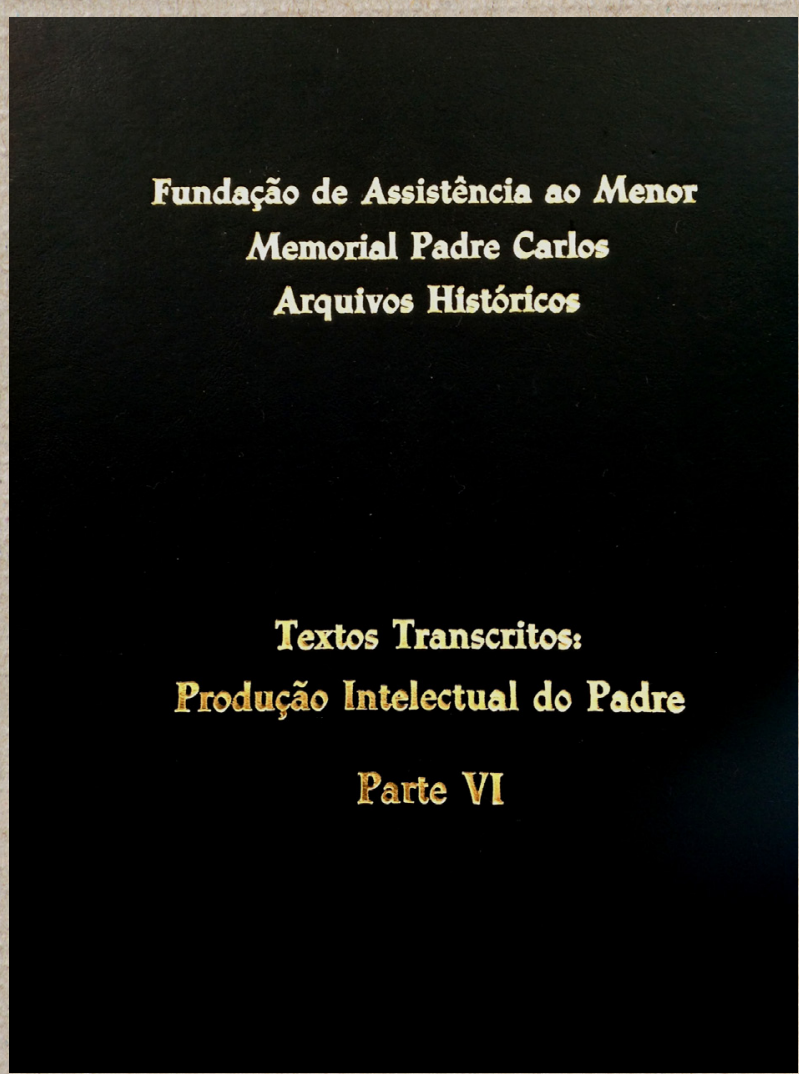

Fonte: Fundação de Assistência Ao Menor. Memorial Pe. Carlos. Escola Profissional Dom Bosco. (Foto: Elaborada pelos autores). livro que foi produzido na Escola Dom Bosco. Todo o processo, desde a digitação das fontes até a encadernação e, o feitio da capa dura com a gravação de letras douradas, foi realizado por alunos nas oficinas profissionalizantes que se mantém na escola

O acervo da Escola Profissional Dom Bosco se encontra organizado em um memorial que traz o nome do fundador da instituição, o Padre Carlos. O projeto de sua criação foi iniciado em 2003, em parceria como Centro de Memória-Unicamp (CMU), e tem se efetivado a partir da capacitação de uma equipe local. 0 acervo é composto por fontes históricas vistas em uma concepção mais ampla, como livros, mapas, material pedagógico, uniformes, documentos oficiais, cartas, fotos, filmes, reália² ${ }^{2}$, depoimentos orais de funcionários dos vários níveis hierárquicos, alunos e comunidade. Paulatinamente, o Memorial, vem se configurando como um local para pesquisa da memória escolar daquela instituição e do contexto local e regional.

Para exemplificar, foram localizados, recuperados e devidamente organiza-

2 É o conjunto de móveis e objetos com significado histórico para casa-museu ou memorial. 
dos diversos livros e documentos oficiais, como também a produção pessoal do fundador da instituição, a sua coleção de selos, aproximadamiente 5 mil fotografias, várias partituras de músicas, trabalhos manuais realizados nas oficinas, moldes utilizados pelos professores em suas aulas práticas e, ainda, uma série de slides e filmes 16 $\mathrm{mm}$, registrando desde o início da Escola até um período mais recente.

Os escritos do Pe. Carlos, que tinha o hábito de toda noite discorrer sobre assuntos diversos, se encontram à espera de um profissional, seja da história ou de outra área, para analisar o seu conteúdo e dar sentido e significado às suas palavras e aos conceitos por ele criados. A seguir, transcrevemos o que o religioso escreveu sobre o que é História, um texto que já foi digitado e se encontra nas páginas da parte VI da Produção Intelectual do Padre:

Assunto: Reflexões sobre a História Humana

Página 27 de fevereiro

$04 / 06 / 1980$

História acontece sem programação,

Quando menos se espera acontecer.
Se fosse propriedade dos historiadores

Ela não seria mais história, mas estória.

A pessoa humana é a própria história.

Que a mão do homem quando escreve história

Somente maneja o ato e atualiza o fato.

Deixa o homem naquilo que ele toca apena um sinal identificador, pessoal e livre.

(Abrir as comportas, libertar as águas não é tarefa que, assumida compromete)

A (sua) busca séria recompõe o estar ciente, interpreta (comunica) o sucesso no seu habitat, no seu tempo transmite para as gerações vindouras como viu (o que) achou, o fato de ontem com os olhos de hoje.

História é vida que salta do papel, encarnada na continuidade de quem vive o presente, encasulada nos que vão viver depois.

História é o sentido que demora imperecível na venerável tradiçãó e na reina do tempo estafeta que chega e parte imediatamente trazendo os dados do fim do dia levando os fatos que apenas amanheceram.

História não é de ontem, de hoje, ou amanhã, mas de toda hora, tempo e lugar escrita no viver pessoal de cada um.

Unidade de inconfundíveis unidades unidas na composição do mesmo texto decodificado para a compreensão final. 
História, reșumo de vidas, lição de humanidade, mensagem cristã

Transporte vivo, ressurreição do humano, atualização do Cristo.

História, desmoronamento das muralhas do tempo de Jericó, concentração no vale permanente (presente) de Josafá, consagração do positivo assumido (permanente) em Canaã.

História, despojamento do supérfluo, vestição do essencial, glorificação do permanente.

Desguarnecimento das atavias efêmeras, impregnação da claridade perpetuação da verdade.

História, gotas eternas cristalizadas em dais, estátua permanente no pedestal do tempo:

Assunto: Valor da Liberdade

Página 01 de março

$06 / 06 / 1980$

(MEMORIAL PADRE CARLOS, Produção Intelectual do Padre, p. 27).

Várias poderão ser as análises do que é História na perspectiva do Pe. Carlos, sendo que, acima da visão religiosa dos fatos, está também uma conceituação mundana, quàndo ela é permeada por uma liberdade que se aproxima de um livre arbítrio em que os acontecimentos não são controlados por um ente superior, mas seguem um percurso livre e espontâneo. Equem é e como procede aquele que se debruça sobre o passado e tenta reescrevê-lo em suas entrelinhas? Para o religioso, o homem e a mulher em si são a história propriamente dita, pois se diferem dos restantes dos animais, pois dão sentido e significado ao que produzem e fazem. O procedimento de ambos ao escrever a história é simplesmente manejar o ato e atualizar o fato, apontando a sua neutralidade em querer entender o acontecido por meio de uma lógica subjetiva, ou acrescentar algo que não foi ou não se aproxima da forma como realmente aconteceu. Por isso é papel do historiador tocar apenas um sinal identificador, pessoal e livre, ou seja, escrever a partir do que lhe está sendo revelado e não se perder em deduções fantasiosas ou meramente inventivas.

A professora Olga Rodrigues de Moraes von Simson, diretora do Centro de Memória - Unicamp no período da organização do memorial, fez um pronunciamento na formação que foi realizada em 13 de agosto de 2005 com as pessoas envolvidas no projeto: 
Eu queria retomar um pouquinho com vocês um passo que a gente já trilhou na construção desse Memorial e na elaboração de todo o material que foi todo trabalhado, organizado e preparado para constituir o Memorial. Foi um longo caminho, um caminho de grandes trocas entre a equipe do Centro de Memória e a equipe da escola, de conhecimento e aprofundamento na figura do Padre Carlos, da Dona Maria, da trajetória que eles construíram aqui e tão importante em Poços de Caldas. Temos já constituídos no Memorial diferentes acervos: organizados, catalogados e prontos para serem na verdade conhecidos e divulgados. $O$ Memorial contendo uma série de informações sobre o passado, sobre um determinado tema, qualquer que seja ele, só tem razão de ser, se for capaz de fazer circular as informações que contém. Caso não possua uma política de circulação da informação, ele perde sua razão de ser. Ele é coisa morta, não tendo, na verdade, função na vida cotidiana da escola, da comunidade, da instituição e da sociedade em geral. Então nós estamos agora iniciando essa segunda fase, que se preocupa com a circulação das informações que esses objetos, que esses fragmentos do passado, seja uma fotografia, seja um depoimento oral, seja um texto escrito, seja uma coleção de objetos. Se esses documentos não contarem essa história, se essas informações não chegarem para os alunos, para os professores, para a comunidade de Poços de Caldas e para a comunidade da região e da nação, o Memorial perde seu objetivo. Então, à preocupação nossa agora é como elaborar uma polí- tica de circulação das informações que o Memorial contém. Mas isso'tudo tem que ser pensado com muito cuidado, porque esse material tem que ser, na verdade, protegido para não se perder. Porque essas informações são importantes para nós hoje e muito importantes, mas serão muito importantes também paras as novas gerações (ALVISI, 2008, p. 247).

\section{O Memorial Padre Carlos encontra-} -se organizado no seguinte formato: Biblioteca e Reália, constituídas pelo acervo da biblioteca e todos os objetos com valor histórico; Documentos Textuais, que inclui a organização e o arquivamento de toda a documentação da escola, da fundação que a mantém e de seus fundadores, além de livros, manuscritos e impressos (mapas, materiais didáticos etc.); Conservação e preservação dos livros, manuscritos e impressos e documentação iconográfica, que engloba toda a parte de conservação e organização dos documentos textuais, e ainda dos filmes, fotografias e slides; Banco de História Oral, que é um arquivo de fitas cassete e fitas de vídeo com depoimentos de ex-alunos e ex-professores, ex-funcionários e membros da comunidade, que relatam suas relações com a escola e a sua influência comunitária. 
Vale ressaltar que a variedade de fontes proporciona uma ampliação de possibilidades para o trabalho do historiador, desde que ele tome o devido cuidado para o afastamento da fragmentação na elaboração do conhecimento:

Todo este alargamento de objetos, fontes e abordagens da pesquisa histórica veio acompanhado de uma crescente, e cada vez mais contundente, crítica historiografia considerada acima de tudo, oficial. Aquela historiografia dos fatos políticos, dos heróis das elites e dos vencedores poderosos. Ou uma crítica àquela historiografia baseada em fatos apresentados rigorosamente em uma certa ordem cronológica e com os quais se relacionam alguns personagens isolados. [... Uma historiografia sem contexto (SANFELICE, 2005b, p. 190).

Sobre a ampliação dos tipos de documentos, o autor afirma que as novas abordagens históricas trouxeram a utilização das fontes mais variadas, como fotos, cadernos, mobiliários, plantas, prédios, o que possibilita a exploração de vários olhares sobre o trabalho, mas que deve estar sempre levando em consideração as perguntas pertinentes para se apropriar dos tipos de fontes disponíveis. Ressalta, ainda, a importância de um empenho maior na criação de condições obje- tivas para uma política de preservação das fontes históricas escolares, de modo a contribuir para o avanço do campo da pesquisa nessas instituições (SANFELICE, 2005b).

O fundador da Escola, Pe. Carlos, em um de seus depoimentos, fez uma referência que nos permite refletir sobre o tipo de proposta educativa que pode estar embutida na trajetória dessa instituição escolar, dizendo que, na Escola Profissional Dom Bosco, se pratica a "Educação pelo trabalho e não para o trabalho" (ALVISI, 2001).

\section{Considerações finais}

A parceria entre o Centro de Memória - Unicamp e a Escola Profissional Dom Bósco, de Poços de Caldas, foi fundamental para o surgimento do Memorial Pe. Carlos, principalmente após a participação de historiadores e pesquisadores que passaram a auxiliar sua construção, como também a escrever a história da escola a partir das diversas materialidades arquivadas em seu recinto. 
Há poucos memoriais escolares ou de outra ordem existentes no Brasil, mas têm surgido iniciativas importantes, até mesmo de empresas, que demionstram a preocupação com a história, com a memória e com a materialidade memorialística empresarial.

O Memorial Pe. Carlos é um indicativo de como outros memoriais podem se efetivar em vários espaços e instituições, principalmente a partir da parti- cipação da comunidade interna ou externa, bem como da disponibilidade das universidades em estabelecer par-, cerias, oferecendo seus conhecimentos técnicos e uma ampliação da visão historiográfica, pois, para a compreensão da história, se faz necessário e urgente o processo de preservação da memória passada, ou recente, de uma instituição de ensino em suas relações com a sociedade.

\section{Referências}

ALVISI, Lílian de Cássia. Memórias de Vivências Escolares em Poços de Caldas/MG: Escola Profissional Dom Bosco (1946-1.960). 2001. Dissertação (Mestrado em Educação) - Universidade Estadual de Campinas, Campinas. 2001.

Memória, Resistência e Empoderamento: a constituição do Memorial Escolar Padre Carlos de Poços de Caldas/MC. 2008. 329 fls. Tese (Doutorado em Educação)-Universidade Estadual de Campinas, Campinas. 2008.

CARVALHO, Jussara Callindo Mariano de. História, trabalho e educação profissional nó Brasil (EPDB - Poços de Caldas - MG). 2008.171 fls. Dissertação (Mestrado em Educação) - Universidade Estadual de Campinas, Campinas. 2008.

CASTANHO, Sergio Eduardo Montes. Institucionalização das Instituições Escolares: final do Império e Primeira República no Brasil. In: NASCIMENTO, Maria Isabel Moura et al. (Orgs.). Instituições Escolares no Brasil: conceito e reconstrução histórica. Campinas: Autores Associados/ HISTEDBR; Sorocaba: Uniso; Ponta Grossa: UEPC, 2007.

CENTRO DE MEMÓRIA - UNICAMP. Relatório-Memorial Escola Profissional Dom Bosco em Poços de Caldas. (Mimeo). Poços de Caldas, 2003.

ESCOLA PROFISSIONAL DOM BOSCO. Edição comemorativa dos 30 anos da escola. Poços de Caldas: Cráfica Dom Bosco, 7976. 
Site da Escola Profissional Dom Bosco. Poços de Caldas. Disponível em: <http://www.escoladombosco.com.br>. Acesso em: dez. 2016

FUNDAÇÃO DE ASSISTÊNCIA AO MENOR. Memorial Padre Carlos. Arquivos Históricos. Textos , transcritos. Produção Interna do Pe. Parte I. [198?]. Digitalizado. Escola Profissional Dom Bosco.

FURTADO, Alessandra Cristina. Os Arquivos Escolares e suã Documentação: possibilidades e limites para a pesquisa em História da Educação. InCID: Revista de Ciência da Informação e Documentação, Ribeirão Preto, v. 2, n. 2, p. 145-159, dez. 2017. ISSN 2178-2075. Disponível em: <http://www.revistas.usp.br/incid/article/view/42357>. Acesso em: 20 jan. 2017. DOl: http:// dx.doi.org/10.11606/issn.2178-2075.v2i2p145-159.

MAGALHÃES, J. A história das instituições educacionais em perspectiva. In: CATTI JÚNIOR, D.; INÁCIO FILHO, G. (Orgs.). História da educação em perspectiva: ensino pesquisa, produção e novas investigações. Campinas: Autores Associados; Uberlândia: Edufu, 2005.

MEDEIROS, Ruy Hermann de Araújo. Arquivos escolares - breve introdução a seu connecimento. Revista HISTEDBR on line, Campinas, n. 14, jun. 2004. Disponível em: <http://www.histedbr. fe.unicamp.br/navegando/artigos_frames/artigo_096.html>. Acesso em: 20 jan. 2017

MICUEL, Maria E. B. Os arquivos e fontes como conhecimento da história da instituições escolares. In: NASCIMENTO, Maria Isabel Moura et al. (Orgs.). Instituições Escolares no Brasil: conceito e reconstrução histórica. Campinas: Autores Associados/HISTEDBR; Sorocaba: Uniso; Ponta Grossa: UEPG, 2007.

MOGARRO, Maria ]oão. Arquivos e Educação: a construção da memória educativa. Revista Brasileira de História da Educação, [S.7], v. 5, n. 2 [10], jul./dez. 2005. Disponível em: <http://www. rbhe.sbhe.org.br/index.php/rbhe/article/view/169/177>. Acesso em: dez. 2016.

NORONHA, Olinda Maria. Historiografia das instituições escolares: contribuição. In: NASCIMENTO, Maria Isabel Moura et.al. (Orgs.). Instituições Escolares no Brasil: conceito e reconstrução histórica. Campinas: Autores Associados/HISTEDBR; Sorocabba: UNISO; Ponta Grossa: UEPC, 2007. p. 165-173

SANFELICE, José Luíz. História das instituições escolares e gestores educacionais. In: BITTENCOURT, A. B.; OLIVEIRA JR., W. M. (Orgs.). Estudo, Pensamento e Criação. Campinas: Faculdade de Educação/Unicamp, 2005b. v. 2. [Livro II].

História das instituições escolares. In: NASCIMENTO, Maria Isabel Moura et al. (Orgs.). Instituições Escolares no Brasil: conceito e reconstrução histórica. Campinas: Autores Associados/ HISTEDBR; Sorocaba: UNISO; Ponta Grossa: UEPG, 2007.

SANTOS, Rafael Pereira dos. Oinício do Ensino Privado Confessional na cidade de Petrolina (1920-1930). 2015. Monografia (Bacharelado em História) - Universidade de Pernambuco, Petrolina. 2015. 
SAVIANI, Dermeval. Política e Educação no Brasil: o papel do Congresso Nacional na legislação do ensino. São Paulo: Cortez; Autores Associados, 7988.

O trabalho como princípio educativo frente às novas tecnologias. In: FERRETI, J. C. et al. (Orgs.). Tecnologias, Trabalho e Educação: um debate multidisciplinar. 8. ed. Petrópolis: Vozes, 1994.

Instituições escolares no Brasil: Cónceito e reconstrução histórica. In: NASCIMENTO, Maria Isabel Moura et al. (Orgs.). Instituições Escolares no Brasil: conceito e reconstrução histórica. Campinas: Autores Associados/HISTEDBR; Sorocaba: UNISO; Ponta Grossa: UEPC, 2007.

VIDAL, Diana C. Por uma ampliação da noção de documento escolar. In: NASCIMENTO, Maria Isabel Moura et al. (Orgs.). Instituições Escolares no Brasil: conceito e reconstrução histórica. Campinas: Autores Associados/HISTEDBR; Sorocaba: UNISO; Ponta Grossa: UEPG, 2007. 